\title{
Persistent systemic inflammatory response after stent insertion in patients with malignant bile duct obstruction
}

\author{
A B Ballinger, J A Woolley, M Ahmed, H Mulcahy, E M Alstead, J Landon, M L Clark, \\ M J G Farthing
}

\begin{abstract}
Background-Surgery in patients with malignant bile duct obstruction is associated with high postoperative morbidity and mortality. Tumour necrosis factor $\alpha$ (TNF- $\alpha$ ) plays a key role in the pathogenesis of these complications.

Aims-To determine the effect of biliary drainage on plasma concentrations of TNF- $\alpha$, its soluble circulating receptors (sTNFr), and other proinflammatory cytokines.

Methods-Plasma concentrations of TNF- $\alpha$, sTNFr-P75, interleukin 6 (IL-6), and IL-1 $\alpha$ were measured in 25 patients with malignant bile duct obstruction before and after endoscopic stent insertion. Results-Mean serum bilirubin was 157 $\mu \mathrm{mol} / 1$ before stent insertion and 35.2 $\mu \mathrm{mol} / 1$ one week post stent insertion. There was complete relief of jaundice in $77 \%$ of patients by four weeks. Plasma concentrations of TNF- $\alpha$ and IL-1 $\alpha$ were below the detection limit of the assays in all samples. Median plasma sTNFr-P75 in the cancer patients was $960 \mathrm{ng} / \mathrm{l}$ (range 400-6600) before stent insertion and remained unchanged at one and four weeks after stenting. Plasma sTNFr-P75 in cancer patients was significantly higher $(\mathrm{p}<0.01)$ than in healthy controls $(250$ (200-650) ng/l). Before stent insertion, plasma IL-6 concentrations were detectable (above $5 \mathrm{ng} / \mathrm{l})$ in $17(68 \%)$ patients. After relief of biliary obstruction IL-6 levels fell from a prestent median of 13.2 to less than $5 \mathrm{ng} / \mathrm{l}$ at one week after stent insertion. Plasma concentrations of IL-6 were undetectable in $76 \%$ of patients at this time.

Conclusion-Activation of the TNF/sTNFr complex is unchanged after biliary drainage in patients with malignant bile duct obstruction. This may explain why preoperative drainage does not influence the high morbidity and mortality associated with surgery in these patients. (Gut 1998;42:555-559)
\end{abstract}

Keywords: jaundice; tumour necrosis factor $\alpha$; biliary drainage; pancreatic cancer

Surgery in patients with malignant bile duct obstruction is associated with a high prevalence of postoperative complications and mortality rates varying from 5 to $27 \% .^{1-3}$ The complica- tions include sepsis, cardiovascular instability, and acute renal failure. Renal failure occurs in $8-10 \%$ of patients requiring surgery and contributes to eventual mortality in $70-80 \%$ of those who develop it. ${ }^{4}$ Evidence from animal studies suggests that tumour necrosis factor $\alpha$ $(\mathrm{TNF}-\alpha)$ plays a central role in the pathogenesis of the complications seen after surgery..$^{5-7}$ Animals with ligated bile ducts have high circulating concentrations of TNF- $\alpha$ and the concentrations are further increased by surgical trauma. Bemelmans et al found that the concentrations of a circulating soluble TNF- $\alpha$ receptor were positively correlated with surgical mortality. ${ }^{5}$ Finally, administration of lactulose preoperatively, which reduces endotoxin induced TNF- $\alpha$ release, significantly reduced the surgical mortality rate of biliary obstructed mice. $^{6}$

It is thought that increased TNF- $\alpha$ production with biliary obstruction may result from high concentrations of circulating endotoxin. ${ }^{8-10}$ The absence of bile in the gut results in intestinal barrier dysfunction and the passage of endotoxin into the portal system. ${ }^{11}$ This, together with impaired clearance of endotoxin by liver Kupffer cells, ${ }^{12}$ leads to systemic endotoxaemia. More recently, Clements et al have shown evidence of bacterial translocation to the mesenteric lymph nodes by one week after bile duct ligation in rats. The organism most often retrieved from the lymph nodes was Escherichia coli. By three weeks after surgery, translocation was more widespread and positive cultures were obtained from the liver, lungs, and spleen as well as lymph nodes. ${ }^{13}$

Endotoxins stimulate the release of a variety of proinflammatory mediators including TNF- $\alpha$, interleukin 1 (IL-1), thromboxane A, and platelet activating factor. ${ }^{14-17}$ In both animals and humans, administration of TNF- $\alpha$ antibodies often reverses the cardiovascular and other effects induced by endotoxin, thus suggesting that TNF- $\alpha$ is the primary mediator of the systemic effects of endotoxin. ${ }^{14}{ }^{15}$ Endotoxin also liberates the extracellular part of membrane bound TNF- $\alpha$ receptors which can be detected in high concentrations in the circulation as soluble $\mathrm{TNF}-\alpha$ receptors (sTNFr). Soluble TNF receptors bind free circulating TNF- $\alpha$ and these complexes may behave as slow release reservoirs of TNF leading to an ongoing inflammatory response. ${ }^{18}$ Measurement of plasma concentrations of sTNFr may provide a better indicator of the 
activation state of the $\mathrm{TNF}-\alpha / \mathrm{TNFr}$ system than measurement of plasma TNF- $\alpha$ concentrations alone.

Based on the observations which have been made in jaundiced animals and humans, preoperative internal biliary drainage would be expected to restore Kupffer cell function and the integrity of the intestinal mucosal barrier. This would lead in turn to a reduction in systemic endotoxaemia, and we would expect a fall in cytokine activation with a decrease in surgical morbidity and mortality. Animals with ligated bile ducts have high circulating concentrations of endotoxin and this is reversed by internal biliary drainage..$^{919}$ Furthermore, Bemelmans et al have reported increased circulating sTNFr concentrations in jaundiced mice but it is not known whether the levels fall with relief of obstruction. ${ }^{7}$ However, the benefits predicted from these animal studies have not consistently been borne out in clinical practice. In the most recent study, Lai et al reported no improvement in postoperative morbidity or mortality in patients who had preoperative endoscopic biliary drainage for malignant obstructive jaundice compared with those who had no preoperative biliary decompression. ${ }^{20}$

The aim of our study was therefore to determine whether internal biliary drainage does indeed result in the predicted fall in plasma cytokine concentrations in patients with malignant bile duct obstruction.

We have measured serum concentrations of TNF $\alpha$, IL- 6 , and IL- $1 \alpha$ in patients with malignant bile duct obstruction before and after endoscopic stent insertion. We have also measured plasma concentrations of one of the cell surface receptors for TNF- $\alpha$, sTNFr-P75, a 75 $\mathrm{kDa}$ protein which circulates in soluble form.

\section{Patients and methods}

This study was approved by the Research Ethics Committees of the Waltham Forest Health Authority and City and Hackney Health Authority. Patients were recruited from St Bartholomew's Hospital and Whipps Cross Hospital and all patients gave informed consent before entering the study. Between I July 1993 and 1 January 1995, patients with cancer of the head of pancreas, referred for endoscopic retrograde cholangiopancreatography (ERCP) and stent insertion were recruited for the study. Diagnosis was initially based on a typical history and the presence of a mass in the head of the pancreas and dilated bile ducts on ultrasound examination or computed tomography. This has been shown to be sensitive and specific for the diagnosis of pancreatic cancer and cytology/histology is not necessary to make a definite diagnosis. ${ }^{21}$ In most of our patients, however, a tissue diagnosis was made at the first ERCP or at a later date. Patients were seen before stent insertion and then at one and four weeks after stent insertion or until death if this occurred before four weeks. On each occasion venous blood samples were taken for subsequent measurement of serum urea and electrolytes, liver biochemistry, and cytokine concentrations. In addition $8 \mathrm{ml}$ of blood was collected from a peripheral vein for routine aerobic and anaerobic culture. Blood for cytokine concentrations was collected into cold EDTA bottles and kept on ice (always for less than 10 minutes) until centrifugation at $2000 \mathrm{~g}$ for 10 minutes. The plasma obtained was flash frozen and stored at $-20^{\circ} \mathrm{C}$ until assayed. Control blood samples were taken from 10 age and sex matched healthy volunteers. The investigators measuring plasma cytokine concentrations were unaware of the diagnosis.

ELISA FOR IL-L $\alpha$ AND TNF- $\alpha$

Plasma concentrations of IL- $1 \alpha$ and TNF- $\alpha$ were measured by enzyme linked immunosorbent assay (ELISA; Biotrak RPN 2140 (IL-1 $\alpha$ ) and RPN 2148 (TNF- $\alpha$ ), Amersham International plc) with minimum detection limits of $0.2 \mathrm{ng} / 1$ and $15.7 \mathrm{ng} / 1$ respectively.

ELISA FOR SOLUBLE TNF RECEPTORS

sTNFr-P75 was measured using a sensitive and specific human ELISA (Bender MedSystems, Bender \& Co. GmbH, Austria) with a detection limit of $0.15 \mu \mathrm{g} / 1$.

IMMUNORADIOMETRIC ASSAY FOR IL-6

Plasma concentrations of IL- 6 were measured using a sensitive and specific immunoradiometric assay (IRMA) or by ELISA (BenderMed systems). The IRMA has been established and validated in the Department of Chemical Pathology, St Bartholomew's and The Royal London School of Medicine and Dentistry. The assay did not cross react with an excess of IL-1 $\alpha$, IL-1 $\beta$, IL-2, IL-4, IL-5, IL-8, IL-11, TNF- $\alpha$, TNF- $\beta$, or interferon $\gamma$ and showed linearity with the recombinant glycosylated international IL-6 reference preparation $(89 / 548)$ and with diluted patient samples. The interassay precision $(\% \mathrm{cv})$ of the IRMA for mean concentrations of recombinant human IL-6 of $0.477,4.576$, and $8.823 \mu \mathrm{g} / 1$ was $4.9,2.8$, and $3.9 \%$ respectively; intra-assay precision was $3.5,1.8$, and $1.5 \%$ for IL- 6 concentrations of $0.06,0.5$ and $5 \mu \mathrm{g} / 1$ respectively. The minimum detection limit for IL-6 in human plasma was $5 \mathrm{ng} / 1$ using the IRMA and $4 \mathrm{ng} / \mathrm{l}$ with the ELISA. The high bilirubin concentrations in the patient plasma samples were shown not to interfere with the measurements of these cytokines and receptors.

\section{STATISTICAL ANALYSIS}

In all cases plasma cytokine measurements represent the mean of duplicate values. Cytokine concentrations in patient groups at different time points are expressed as medians and range unless stated otherwise. The results before and after stent insertion have been compared using the Mann-Whitney U test for nonparametric data. All results were considered to be statistically significant at the $5 \%$ level.

\section{Results}

During the study period 38 patients were referred with obstructive jaundice due to malignant obstruction of the common bile duct. Thirteen of these patients were not included in this study for the following reasons. Eight patients had obstruction of the 


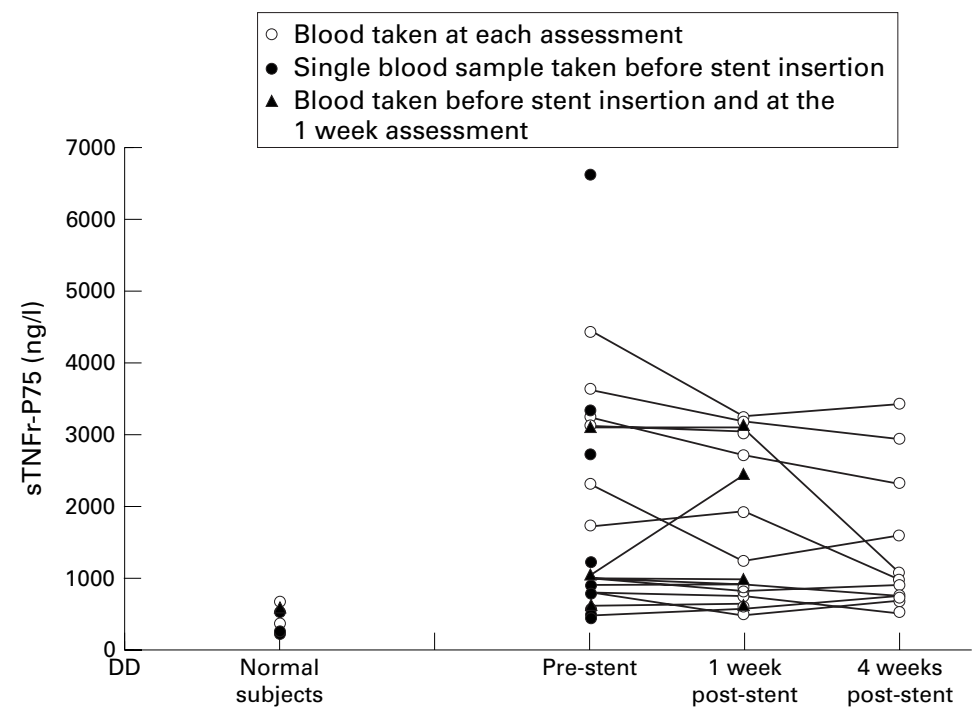

Figure 1 Effect of stent insertion on plasma sTNFr concentrations. Patients who had blood taken at each assessment are represented by open circles; patients who had only a single sample taken before stent insertion are represented by closed circles; and patients who had blood samples before stent insertion and at the one week assessment are represented by closed triangles.

duodenum causing gastric outflow obstruction or precluding passage of the endoscope through the duodenum. In three patients stent insertion was not possible due to technical difficulties. Thus, in total 11 patients were referred for a surgical bypass procedure. Two patients did not want to take part in the study. The 13 patients who could not be stented did not differ in their characteristics (mean age 68, range 54-92 years; mean serum bilirubin 171 $\mu \mathrm{mol} / \mathrm{l})$ to the patients who are the subject of the study. Furthermore, plasma concentrations of sTNFr-P75 did not differ between the 13 patients and the study group.

Twenty five patients (12 men) with jaundice secondary to cancer of the head of pancreas are the subject of this study. The mean age of the patients at presentation was 74 years (range 48-89). Plasma concentrations of sTNFr and

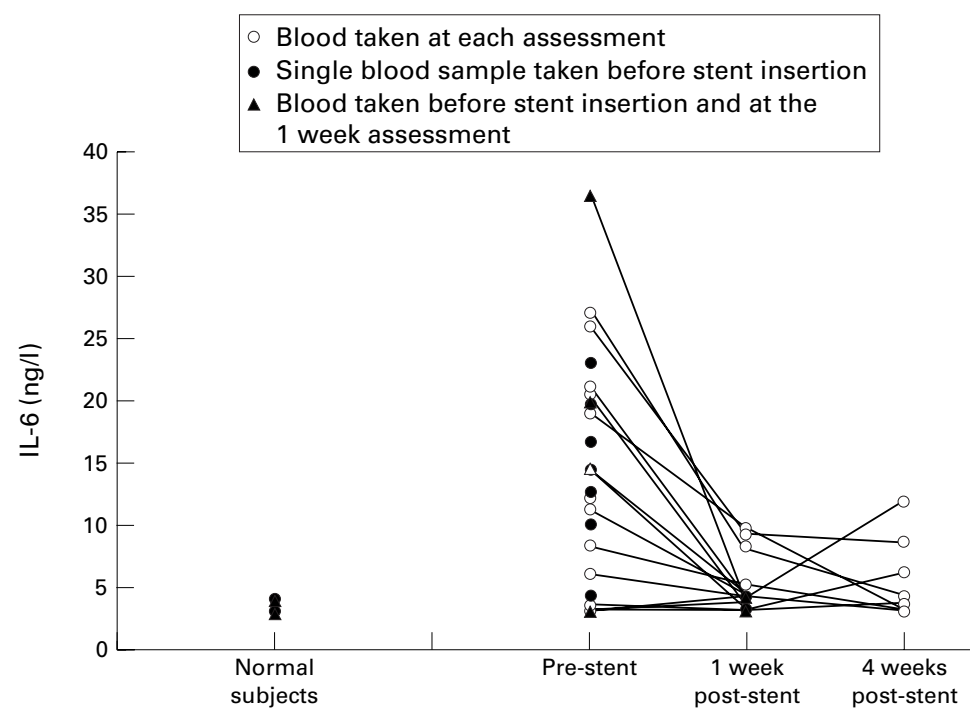

Figure 2 Effect of stent insertion on plasma IL-6 concentrations. Patients who had blood taken at each assessment are represented by open circles; patients who had only a single sample taken before stent insertion are represented by closed circles; and patients who had blood samples before stent insertion and at the one week assessment are represented by closed triangles.
IL-6 were measured in all patients before stent insertion, and in 16 and 11 of these patients at one week and four weeks respectively after stent insertion. The reduction in patient numbers was the result of a combination of factors: some patients moved out of the area for their remaining weeks of life and were lost to follow up; three patients died within two weeks of stent insertion; and some patients declined to have further blood samples taken. Blood cultures were taken and plasma concentrations of TNF- $\alpha$ and IL- $1 \alpha$ were measured in 16 of the 25 patients before stent insertion.

Mean serum bilirubin in the cancer patients was $157 \mu \mathrm{mol} / 1$ before stent insertion and fell to $35.2 \mu \mathrm{mol} / 1$ by one week post stent insertion (95\% confidence interval 60 to $273, \mathrm{p}<0.003$ (paired $t$ test)). There was complete relief of jaundice in 10 of the 13 patients who were alive and under follow up at the four week assessment. Eight (32\%) patients had abnormal renal function before stent insertion and this did not improve after biliary drainage. In these eight patients the mean serum creatinine was $135 \mu \mathrm{mol} / 1$ (range 110-203) before stent insertion and $129 \mu \mathrm{mol} / 1$ (102-195) after stent insertion. There was no growth from peripheral blood cultures in the 16 patients who were studied before stent insertion. After stent insertion five patients had evidence of sepsis with a fever of $38-39^{\circ} \mathrm{C}$ and rigors in three patients. Sepsis occurred one, four, four, five, and nine days respectively after stent insertion and was treated promptly with antibiotics. Only one of these patients had positive blood cultures with a growth of $E$ coli. The episodes of sepsis were thought to be related to the biliary stent except in one patient who also had a urinary tract infection. Two of the five patients with sepsis died and sepsis was thought to be at least a contributing factor.

The mean age of the 10 healthy controls (five men) was 72 years (range 34-78).

\section{PLASMA CYTOKINE CONCENTRATIONS}

Plasma concentrations of TNF- $\alpha$ and IL $-1 \alpha$ in all patient samples and healthy controls were below the detection limit of both assays. The median plasma sTNFr-P75 concentration in the cancer patients was $960 \mathrm{ng} / 1$ (range 400-6600) before stent insertion and remained unchanged $(\mathrm{p}>0.05)$ at one week (1050 (450$3200) \mathrm{ng} / \mathrm{l}$ ) and at four weeks (950 (550-3400) ng/l) after stenting (fig 1). Plasma sTNFr-P75 concentrations in the cancer patients were significantly higher $(\mathrm{p}<0.01)$ than in healthy controls (250 (200-650) ng/1). There was no significant correlation between the plasma concentration of sTNFr-P75 and serum albumin or serum billrubin.

Plasma concentrations of IL- 6 were below the assay detection limit ( $5 \mathrm{ng} / 1)$ in all healthy controls. Before stent insertion, plasma IL-6 concentrations were detectable (above $5 \mathrm{ng} / 1$ ) in $17(68 \%)$ patients. After relief of biliary obstruction IL-6 levels fell from a prestent median of 13.2 ( $<5$ to 36.9 ) $\mathrm{ng} / 1$ to less than 5 $(<5$ to 15.6$) \mathrm{ng} / 1$ at one week after stent insertion. Plasma concentrations of IL-6 were 
undetectable in $76 \%$ of patients at one week after stent insertion $(\mathrm{p}<0.01)$ (fig 2$)$.

\section{Discussion}

In this study we have shown that there is activation of the TNF- $\alpha / \mathrm{TNF}$ receptor system in patients with malignant bile duct obstruction. It has been proposed that restoration of bile flow to the gut would reduce systemic endotoxaemia and so remove the stimulus for activation of TNF/sTNFr. However, we have found that plasma concentrations of sTNFr are unaltered by internal biliary drainage. In addition, we have found that biliary drainage did not improve renal function in patients with a raised urea and creatinine before stenting. These results may suggest an analogous situation to the "two hit model" that is proposed for patients who develop a "systemic inflammatory response syndrome" and multiple organ failure after severe injury. ${ }^{22}$ In these patients it is proposed that the initial injury (the first hit) primes the inflammatory machinery and then a second insult (the second hit), for example, surgery, triggers the release of powerful mediators such as cytokines. This leads to a systemic inflammatory response with cell death, organ failure, and a resultant high mortality. We would propose that the inflammatory system is primed in patients with malignant bile duct obstruction and in contrast to predicted results this is not reduced by internal biliary drainage. Operative intervention in these patients, with or without prior biliary drainage, is the second insult which leads to a pronounced systemic inflammatory response and contributes to the high morbidity and mortality associated with surgery. In our patients biliary drainage was not performed as a preoperative procedure and therefore we were not able to measure plasma cytokine concentrations after surgery and explore this proposal further. However, the results from mice with ligated bile ducts would support our findings. ${ }^{7}$ In this model plasma concentrations of sTNFr were increased fourfold compared with sham operated controls; a similar increase was seen in our patients compared with controls. In addition sTNFr concentrations were found to be significantly correlated with mortality after surgery in jaundiced mice and surgical trauma resulted in a pronounced further increase in sTNFr concentrations. In patients with the sepsis syndrome non-survival is associated with higher plasma concentrations of sTNRr than in survivors. ${ }^{23}$ Our results and conclusions are in agreement with this study-that is, elevated levels of sTNFr post stent reflect an ongoing inflammatory process which may contribute to a poor outcome after surgical intervention. Although the tumour may stimulate the production of sTNFr it is possible that the stent itself may also lead to an ongoing inflammatory reaction and release of sTNFr. Therefore, the intervention which was intended to improve outcome may, in surgical patients, actually contribute to their demise. This hypothesis would be supported by the temporal relationship between stent insertion and sepsis in five of the study patients suggesting that the stent may stimulate the inflammatory process.

In our study we did not measure plasma endotoxin concentrations before and after stenting, but previous studies have consistently shown that biliary drainage reverses endotoxaemia. It is unclear why biliary drainage reverses endotoxaemia but there is no associated reduction in plasma concentrations of sTNFr. In animal studies, endotoxin concentrations are reduced to control values by two weeks after biliary drainage but it is not known whether levels return to normal before this time. ${ }^{92}$ In patients with obstructive jaundice intestinal permeability is increased compared with control patients and this is reversed by 28 days after relief of biliary obstruction although no such decrease is seen at seven days. ${ }^{24}$ These results support the animal data that gut barrier function is impaired in biliary obstruction and thus predisposes to endotoxaemia. We did not even see a trend towards a reduction in STNFr concentrations by four weeks after stenting, at which time the gut barrier function is likely to have returned to normal. Thus we consider it unlikely that a significant reduction would be seen if patients were followed for a longer time period. We also think it is unlikely that the results and conclusions of our study would have been altered if complete data were available on the patients who were lost to follow up. The characteristics of this group (age, serum billrubin, and serum sTNFr concentrations) before stent insertion were no different from those of patients in whom complete follow up was possible. The number of patients in whom follow up data were not available reflects the difficulty in performing studies in this particular group of patients; they are predominantly frail and elderly and frequent visits to hospital are difficult. Although we tried to minimise this by seeing many of the patients at home this was not possible if they lived some distance from the hospital.

In this study we did not detect an increase in plasma concentrations of free $\mathrm{TNF}-\alpha$ and IL- $\alpha$; this may be because the assays that we have used are unable to measure cytokines which are bound to their respective soluble receptors or other binding proteins. Plasma IL-6 concentrations were raised in 17 of the patients before stenting and the concentrations were undetectable in $76 \%$ of patients by one week after stent insertion. This is in contrast to the sTNFr concentrations and reflects the control of IL- 6 secretion by multiple pathways.

In summary, our study shows that in patients with malignant bile duct obstruction, activation of the TNF/sTNFr complex is unchanged after endoscopic stent insertion and may explain why preoperative biliary drainage does not influence the high morbidity and mortality associated with surgery in these patients.

Supported by the National Association for Crohn's and Colitis, the Magdalene Hughes Endowment Fund and the Ernie Whitelaw Research Fund. ABB was supported by the Joint Research Board of St Bartholomew's Hospital. Part of this work
Ront Research Board of St Bartholomew's Hospital. Part of this work
was presented to the 1994 autumn meeting of the British Sociwas presented to the 1994 autumn meeting of the British Soci-
ety of Gastroenterology and the 1995 annual meeting of the ety of Gastroenterology and the 1995 ann
American Gastroenterological Association. 
1 Pitt HA, Cameron JL, Postier RG, et al. Factors affecting mortality in biliary tract surgery. Am f Surg 1981;141:6672 .

2 Dixon JM, Armstrong CP, Duffy SW. Factors affecting morbidity and mortality after surgery for obstructive jaundice: a review of 373 patients. Gut 1983;24:845-52.

3 Lai ECS, Chu KM, Lo CY, et al. Surgery for malignant obstructive

4 Green J. Better OS. Systemic hypotension and renal failure in obstructive jaundice-mechanistic and therapeutic aspects. $\mathcal{F}$ Am Soc Nephrol 1995;5:1853-71.

5 Bemelmans MHA, Greve JW, Gouma DJ, et al. Cytokines, tumour necrosis factor and interleukin-6 in experimental biliary obstruction in mice. Hepatology 1992;15:1132-6.

6 Bemelmans MHA, Gouma DJ, Greve JW, et al. Effect of antitumour necrosis factor treatment on circulating tumour necrosis factor levels and mortality after surgery in jaundiced mice. Br f Surg 1993;80:1055-8.

7 Bemelmans MHA, Greve JWM, Gouma DJ, et al. Increased concentrations of tumour necrosis factor (TNF) and soluconcentrations of tumour necrosis factor (TNF) and solu-
ble TNF receptors in biliary obstruction in mice; soluble ble TNF receptors in biliary obstruction in mice; soluble TNF receptors
1996;38:447-53.

8 Bailey ME. Endotoxin, bile salts and renal function in obstructive jaundice. Br F Surg 1976;63:774-8.

9 Gouma DJ, Coelho JCU, Fisher JD, et al. Endotoxaemia after relief of biliary obstruction by internal and external drainage in rats. Am f Surg 1986;151:476-9.

10 Cahill CJ, Pain JA, Bailey ME. Bile salts, endotoxin and renal function in obstructive jaundice. Surg Gynecol Obstet 1987;165:518-22.

11 Slocum MM, Sittig KM, Specian RD, et al. Absence of intestinal bile promotes bacterial translocation. Am Surg 1992;58:305-10.

12 Clements WDB, Halliday MI, McCaique $\mathrm{M}$, et al. The effects of extrahepatic obstruction jaundice on Kupffer cell clearance capacity (KCCC). Arch Surg 1993;128:2005 .
13 Clements WDB, Parks R, Erwin P, et al. Role of the gut in the pathophysiology of extrahepatic biliary obstruction. Gut 1996;39:587-93

14 Fahey TJ, Yoshioka T, Shires T, et al. The role of tumour necrosis factor and nitric oxide in the acute cardiovascular response to endotoxin. Ann Surg 1996;223:63-9.

15 Fekade D, Knox K, Hussein K, et al. Prevention of JarischHerxheimer reactions by treatment with antibodies against umor necrosis factor alpha. $N$ Engl f Med 1996;335:311-

15 .
16 Okusawa S, Gelfand JA, Ikejima T, et al. Interleukin-1 induces a shock-like state in rabbits: synergism with tumour necrosis factor and the effect of cyclooxygenase inhibition. F Clin Invest 1988;81:1162-72.

17 Anderson BO, Bensard DD, Alden HH. The role of platelet activating factor and its antagonists in shock, sepsis and multiple organ failure. Surg Gynecol Obstet 1991;172:415-24.

18 Aderka D, Engelmann H, Maor Y, et al. Stabilization of the bioactivity of tumour necrosis factor by its soluble receptors. f Exp Med 1992;175:323-9.

19 Diamond T, Dolan S, Thompson RLE, et al. Development and reversal of endotoxaemia and endotoxin-related death and reversal of endotoxaemia and endotoxin-related

20 Lai ECS, Mok FPT, Fan ST, et al. Preoperative endoscopic drainage for malignant obstructive jaundice. $\mathrm{Br} \mathcal{F}$ Surg 1994;81:1195-8.

21 American Society for Gastrointestinal Endoscopy. ASGE policy and procedure manual. ASGE publication no. 1003. Washington: ASGE, 1990.

22 Moore FA, Moore EE. Evolving concepts in the pathogenesis of postinjury multiple organ failure. Surg Clin North Am 1995;75:257-77.

23 Goldie AS, Fearon KC, Ross JA, et al. Natural cytokine antagonists and endogenous antiendotoxin core antibodies in sepsis syndrome. $\mathscr{f} A M A 1995 ; 274: 172-7$.

24 Parks RW, Clements WDB, Smye MG, et al. Intestinal barrier dysfunction in clinical and experimental obstructive jaundice and its reversal by internal biliary drainage. $\mathrm{Br} \mathcal{F}$ jurg 1996;83:1345-9. 